\title{
ChemComm
}

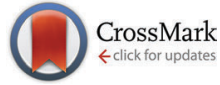

Cite this: Chem. Commun., 2016, 52,4481

Received 21st January 2016

Accepted 25th February 2016

DOI: $10.1039 / c 6 c c 00577 b$

www.rsc.org/chemcomm

\section{Flowerlike $\mathrm{WSe}_{2}$ and $\mathrm{WS}_{2}$ microspheres: one-pot synthesis, formation mechanism and application in heavy metal ion sequestration $\dagger$}

\author{
Wei Li, ${ }^{a}$ Dehong Chen, ${ }^{b}$ Fang Xia, ${ }^{\text {ac }}$ Jeannie Z. Y. Tan, ${ }^{\text {ab }}$ Jingchao Song, ${ }^{\text {ad }}$ \\ Wei-Guo Song ${ }^{\mathrm{e}}$ and Rachel A. Caruso*ab
}

\begin{abstract}
Flowerlike $\mathrm{WSe}_{2}$ and $\mathrm{WS}_{2}$ microspheres were synthesized by a facile and scalable one-pot solvothermal method. Their formation mechanism followed the reaction between dissolved $\mathrm{W}(\mathrm{CO})_{6}$ and dissolved $\mathrm{S}$ or melted Se without complete decomposition of $\mathrm{W}(\mathrm{CO})_{6}$ into tungsten. As novel efficient sorbents, $\mathrm{WSe}_{2}$ and $\mathrm{WS}_{2}$ demonstrated outstanding uptake capacities for $\mathrm{Pb}^{2+}$ and $\mathrm{Hg}^{2+}$.
\end{abstract}

Layered transition metal dichalcogenides (TMDs), $\mathbf{M X}_{2}$ where $\mathbf{M}$ is a transition metal (such as $\mathrm{Mo}, \mathrm{W}$, and $\mathrm{Nb}$ ) and $\mathrm{X}$ is a chalcogen ( $\mathrm{S}$, Se and Te), have received intensive research interest due to their unique electronic, optical, mechanical and chemical properties. ${ }^{1}$ Among them, $\mathrm{WSe}_{2}$ and $\mathrm{WS}_{2}$ have been extensively studied for a variety of applications including valleytronics, ${ }^{2}$ batteries, ${ }^{3}$ electrocatalysis, ${ }^{4}$ photocatalysis, ${ }^{5}$ bioimaging labels, ${ }^{6}$ and electronic devices. ${ }^{7} \mathrm{WSe}_{2}$ and $\mathrm{WS}_{2}$ have a layered structure in the form of $\mathrm{Se}-\mathrm{W}-\mathrm{Se}$ or $\mathrm{S}-\mathrm{W}-\mathrm{S}$ with a $\mathrm{W}$ atomic layer sandwiched by two hexagonal chalcogen atomic layers. ${ }^{4 a, b}$ The interlayers are coupled by weak van der Waals forces and the intralayer $\mathrm{W}-\mathrm{Se} / \mathrm{S}$ bonding is covalent. ${ }^{1}$ Most reports focus on the fabrication of nanosheets/ nanotubes of $\mathrm{WSe}_{2}$ and $\mathrm{WS}_{2}$ by chemical vapor deposition (CVD), electrochemical exfoliation and hot-injection approaches. ${ }^{2-7}$ These methods require high temperature, expensive precursors or toxic $\mathrm{H}_{2} \mathrm{~S} / \mathrm{H}_{2} \mathrm{Se}$, and harsh conditions that give low yields. The growth mechanisms of TMDs have been rarely described, although the formation mechanisms of similar lamellar bismuth chalcogenide materials have been explored. ${ }^{1 e_{2} f}$ Moreover, there are few reports on the construction of three-dimensional (3D)

\footnotetext{
${ }^{a}$ CSIRO Manufacturing, The Commonwealth Scientific and Industrial Research Organization (CSIRO), Clayton South, Victoria, 3169, Australia

${ }^{b}$ Particulate Fluids Processing Centre, School of Chemistry, The University of Melbourne, Parkville, Victoria, 3010, Australia. E-mail: rcaruso@unimelb.edu.au 'School of Engineering and Information Technology, Murdoch University, Murdoch, Western Australia, 6150, Australia

${ }^{d}$ Department of Materials Science and Engineering, Monash University, Clayton, Victoria, 3800, Australia

${ }^{e}$ Beijing National Laboratory for Molecular Sciences (BNLMS), Institute of Chemistry, Chinese Academy of Sciences, Beijing, 100190, P. R. China

$\dagger$ Electronic supplementary information (ESI) available. See DOI: 10.1039/c6cc00577b
}

hierarchical nanosheet-assembled flowerlike architectures of $\mathrm{WSe}_{2}$, although 3D flowerlike $\mathrm{MoS}_{2}$ and metal oxides or hydroxides such as $\mathrm{FeOOH}$ and $\mathrm{AlOOH}$ have been widely studied. ${ }^{8}$ $\mathrm{WS}_{2}$ nanoflowers were produced by using CVD with low yields. ${ }^{9}$ Hierarchical nanosheets assembled into flowerlike structures normally show superior performance in batteries and water treatment. ${ }^{8,10}$ Therefore, it is highly desirable to develop hierarchical $\mathrm{WSe}_{2}$ and $\mathrm{WS}_{2}$ using a facile, cost-effective and scalable approach.

As a new class of heavy metal ion scavenger, metal chalcogenides have been used in heavy metal ion sequestration for water treatment, including $\mathrm{ZnS}, \mathrm{K}_{2 x} \mathrm{Mn}_{x} \mathrm{Sn}_{3-x} \mathrm{~S}_{6},\left(\mathrm{NH}_{4}\right)_{4} \mathrm{In}_{12} \mathrm{Se}_{20}, \mathrm{H}_{2 x} \mathrm{Mn}_{x} \mathrm{Sn}_{3-x} \mathrm{~S}_{6}$ and $\mathrm{H}_{x} \mathrm{Na}_{y} \mathrm{InS}_{z}{ }^{11}$ due to the strong affinity of the chalcogen to heavy metal ions. In this study, flowerlike $\mathrm{WSe}_{2}$ and $\mathrm{WS}_{2}$ microspheres consisting of their corresponding nanosheets were synthesized by a simple, low-cost and high-yield one-pot template-free solvothermal approach. Their growth mechanism was elucidated by in situ synchrotron radiation X-ray diffraction (SR-XRD). $\mathrm{WSe}_{2}$ and $\mathrm{WS}_{2}$ were used in heavy metal ion sequestration for the first time and showed exceptional uptake capacities for $\mathrm{Pb}^{2+}$ and $\mathrm{Hg}^{2+}$, making them ideal candidates for heavy metal remediation in practical water purification.

$\mathrm{WSe}_{2}$ and $\mathrm{WS}_{2}$ were prepared in high yields ( $>3 \mathrm{~g}$ ) by a solvothermal method from the reaction of $\mathrm{W}(\mathrm{CO})_{6}$ and Se or $\mathrm{S}$ powders in $p$-xylene (see details in ESI $\dagger$ ). Fig. 1 shows the scanning electron microscopy (SEM) and transmission electron microscopy (TEM) images of the flowerlike $\mathrm{WSe}_{2}$. The $\mathrm{WSe}_{2}$ sample displays a hierarchical flowerlike micro/nanostructure (Fig. 1). The flowerlike $\mathrm{WSe}_{2}$ is composed of many self-assembled petals that are curly nanosheets (Fig. 1c). These $\mathrm{WSe}_{2}$ nanosheets are $5 \mathrm{~nm}$ in thickness and $300 \mathrm{~nm}$ in width, and are assembled together to form $3 \mathrm{D} \mathrm{WSe}$ flowers with diameters ranging from $500 \mathrm{~nm}$ to $1 \mu \mathrm{m}$. Fig. $1 \mathrm{~d}$ demonstrates that the thin $\mathrm{WSe}_{2}$ nanosheets consist of a few layers ( $<10$ layers) stacking together and the interlayer spacing of the nanosheets is $0.689 \mathrm{~nm}$, corresponding to the (002) plane of the hexagonal $\mathrm{WSe}_{2}$, with slight expansion due to the strain from the layer curvature. ${ }^{3 b}$ The lattice spacing of $0.285 \mathrm{~nm}$ corresponds to the (100) plane of the $2 \mathrm{H}-\mathrm{WSe}_{2}$ phase. The X-ray diffraction 


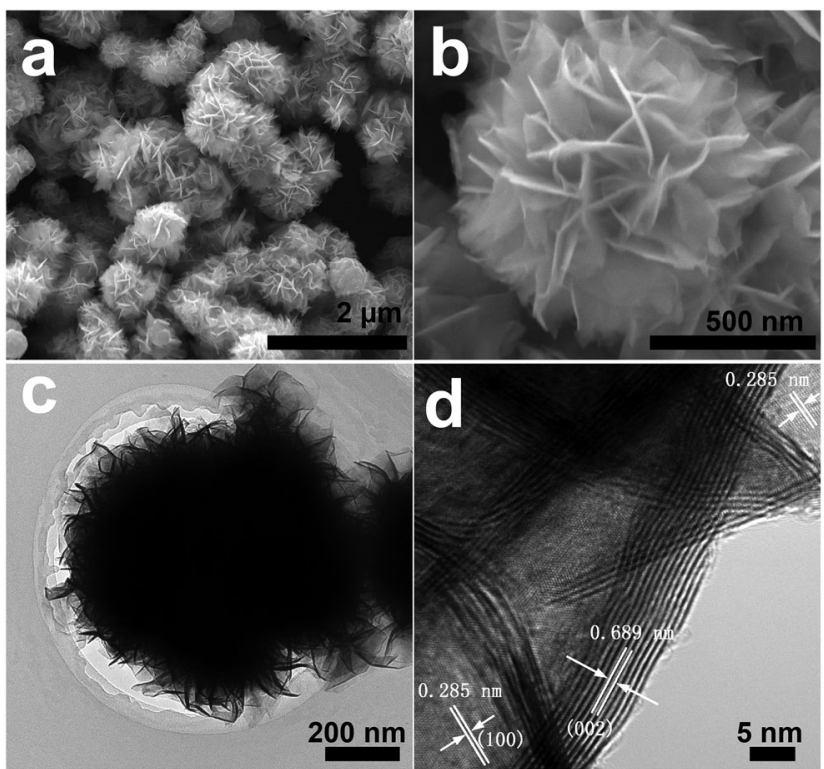

Fig. 1 SEM images ( $a$ and b) and TEM images ( $c$ and d) of the $\mathrm{WSe}_{2}$ microspheres.

(XRD) pattern (Fig. S1a, ESI $\dagger$ ) is indexed to the hexagonal $2 \mathrm{H}-\mathrm{WSe}_{2}$ structure (JCPDS Card No. 38-1388). The energy dispersive X-ray (EDX) spectroscopy confirms the composition of $\mathrm{WSe}_{2}$ with a W/Se atomic ratio of 0.51 (Fig. S1b, ESI $\dagger$ ), in good agreement with the result $(\mathrm{W} / \mathrm{Se}$ atomic ratio $=0.54)$ from inductively coupled plasma optical emission spectroscopy (ICP-OES). The X-ray photoelectron spectroscopy (XPS, Fig. S2, ESI $\dagger$ ) shows that the $\mathrm{W} 4 \mathrm{f}_{7 / 2}(31.9 \mathrm{eV})$ and $\mathrm{W} 4 \mathrm{f}_{5 / 2}(34.0 \mathrm{eV})$ peaks are consistent with previous studies of $\mathrm{WSe}_{2}$ samples. $^{4 a, 12}$ The small peaks at $35.6 \mathrm{eV}$ and $37.8 \mathrm{eV}$ are assigned to $\mathrm{W} 4 \mathrm{f}_{7 / 2}$ and $\mathrm{W} 4 \mathrm{f}_{5 / 2}$ from $\mathrm{WO}_{3}$, likely due to oxidation because of exposure to air during sample preparation and transfer for XPS characterization, and were observed in previous $\mathrm{WSe}_{2}$ reports. ${ }^{4 a, 12}$ The Se $3 \mathrm{~d}$ peak was located at $54.4 \mathrm{eV}$ which could be deconvoluted into $3 \mathrm{~d}_{5 / 2}$ and $3 \mathrm{~d}_{3 / 2}$ peaks.

A similar solvothermal approach using sulfur powder instead of selenium produced a $\mathrm{WS}_{2}$ sample. The product is composed of microspheres with an average diameter of $1 \mu \mathrm{m}$ (Fig. 2a). The $\mathrm{WS}_{2}$ microsphere is comprised of curly nanosheets (Fig. $2 \mathrm{~b}$ and c), yet with smaller width (several tens of nanometers) compared to that of the $\mathrm{WSe}_{2}$ nanosheets. The $\mathrm{WS}_{2}$ nanosheets consist of 5-10 layers and the interlayer distance is $0.647 \mathrm{~nm}$ corresponding to the (002) plane of the hexagonal $\mathrm{WS}_{2}$ (Fig. 2d). The XRD pattern (Fig. S3a, ESI $\dagger$ ) can be assigned to the hexagonal $2 \mathrm{H}-\mathrm{WS}_{2}$ structure (JCPDS Card No. 84-1398), yet with a small shift in (002) peak towards low angle, which is probably caused by the layer curvature. ${ }^{3 b}$ Both the EDX spectroscopy (Fig. S3b, ESI $\dagger$ ) and ICP-OES results show the presence of $\mathrm{W}$ and $\mathrm{S}$ in the $\mathrm{WS}_{2}$ microspheres with a W/S atomic ratio close to 0.5. The XPS spectra (Fig. S4, ESI $\dagger$ ) display the $\mathrm{W} 4 \mathrm{f}_{7 / 2}, \mathrm{~W} 4 \mathrm{f}_{5 / 2}$ and $\mathrm{W} 5 \mathrm{p}_{5 / 2}$ peaks as well as $\mathrm{S} 2 \mathrm{p}$ peak consistent with previous reported $\mathrm{WS}_{2}$ samples, corroborating that the sample is pure $\mathrm{WS}_{2}$ without oxidation. ${ }^{4 b, c, 5 b}$

These results demonstrate that the solvothermal method is efficient in producing nanosheet self-assembled $3 \mathrm{D} \mathrm{WSe}{ }_{2}$ and $\mathrm{WS}_{2}$

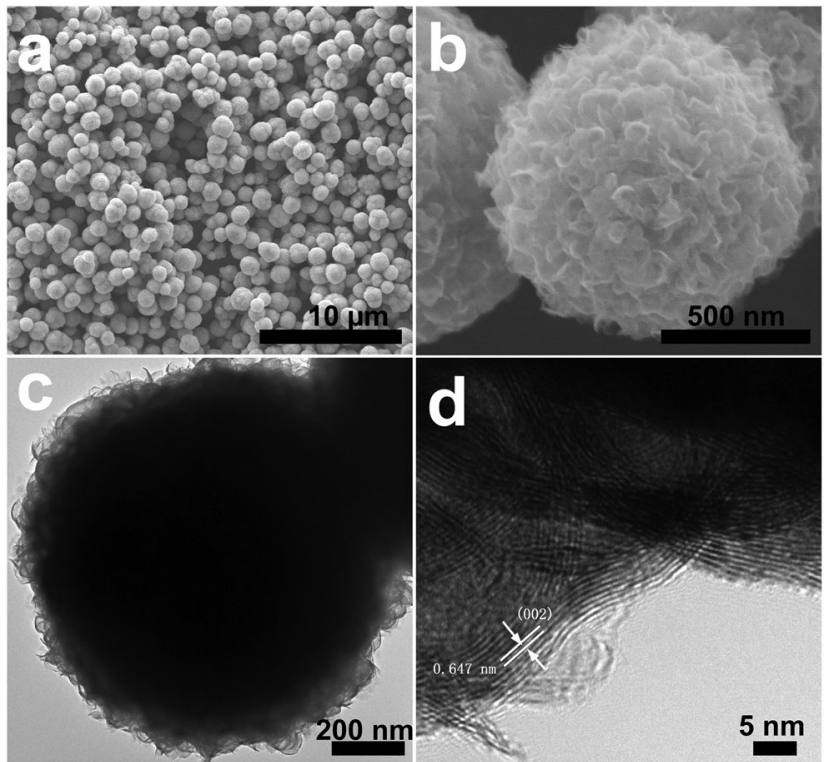

Fig. 2 SEM images ( $a$ and $b$ ) and TEM images ( $c$ and $d$ ) of the $W_{2}$ microspheres.

micro/nanostructures in high yields. The presence of nanosheets in this architecture enhances the surface-to-volume ratio and offers more accessible interfaces for sequestration, while the entire microstructure enables fast and easy sedimentation and separation from water. ${ }^{8 a-c}$

In order to unravel the growth mechanism of flowerlike $\mathrm{WSe}_{2}$ and $\mathrm{WS}_{2}$ microspheres, the synthesis conditions, including temperature and reaction time, were varied and the samples were characterized by SEM and ex situ XRD.

For $\mathrm{WSe}_{2}$, the optimal temperature is $250{ }^{\circ} \mathrm{C}$, which is above the melting point (m.p.) of Se $\left(221^{\circ} \mathrm{C}\right)$. Below $250{ }^{\circ} \mathrm{C}$, there was residual Se in the product (Fig. S5 \& $\mathrm{S} 6, \mathrm{ESI} \dagger$ ). $\mathrm{WS}_{2}$ microspheres formed at $150{ }^{\circ} \mathrm{C}$ and crystallized upon rising temperature and the morphology evolved from irregular microspheres with smooth surfaces to relatively uniform microspheres with a well-defined nanosheet assembly (Fig. S7, ESI $\dagger$ ). At $250{ }^{\circ} \mathrm{C}$, the smooth $\mathrm{WSe}_{2}$ microspheres gradually developed into coarse spheres with improved crystallinity and eventually crystalline flowerlike $\mathrm{WSe}_{2}$ formed (Fig. S8, ESI $\dagger$ ), as the reaction time was prolonged. A similar process also occurred in the growth of $\mathrm{WS}_{2}$ microspheres except that the lateral size of the $\mathrm{WS}_{2}$ nanosheets was smaller than that of the $\mathrm{WSe}_{2}$ nanosheets (Fig. S9, ESI $\dagger$ ). Therefore, for both $\mathrm{WSe}_{2}$ and $\mathrm{WS}_{2}$, smooth microspheres initially formed and then the nanosheets were developed and crystallized on the surface of microspheres under the solvothermal conditions. Duphil et al. reported an ambient solution method to produce merely amorphous $\mathrm{WSe}_{2}$ and $\mathrm{WS}_{2}$ irregular nanoparticles using $\mathrm{W}(\mathrm{CO})_{6}$, Se and $\mathrm{S}$ in p-xylene. ${ }^{13}$ Pol et al. previously reported a high-temperature solid reaction between $\mathrm{W}(\mathrm{CO})_{6}$ and Se to prepare $\mathrm{WSe}_{2}$ nanoparticles. ${ }^{14}$ They both proposed a two-step reaction mechanism involving first the complete decomposition of $\mathrm{W}(\mathrm{CO})_{6}$ into $\mathrm{W}$ and subsequent reaction of $\mathrm{W}$ with $\mathrm{Se} / \mathrm{S}$ without giving direct evidence. In the absence of Se or $\mathrm{S}, \mathrm{W}(\mathrm{CO})_{6}$ was heated at varying temperatures in $p$-xylene in a Teflon-lined autoclave. The resultant products 


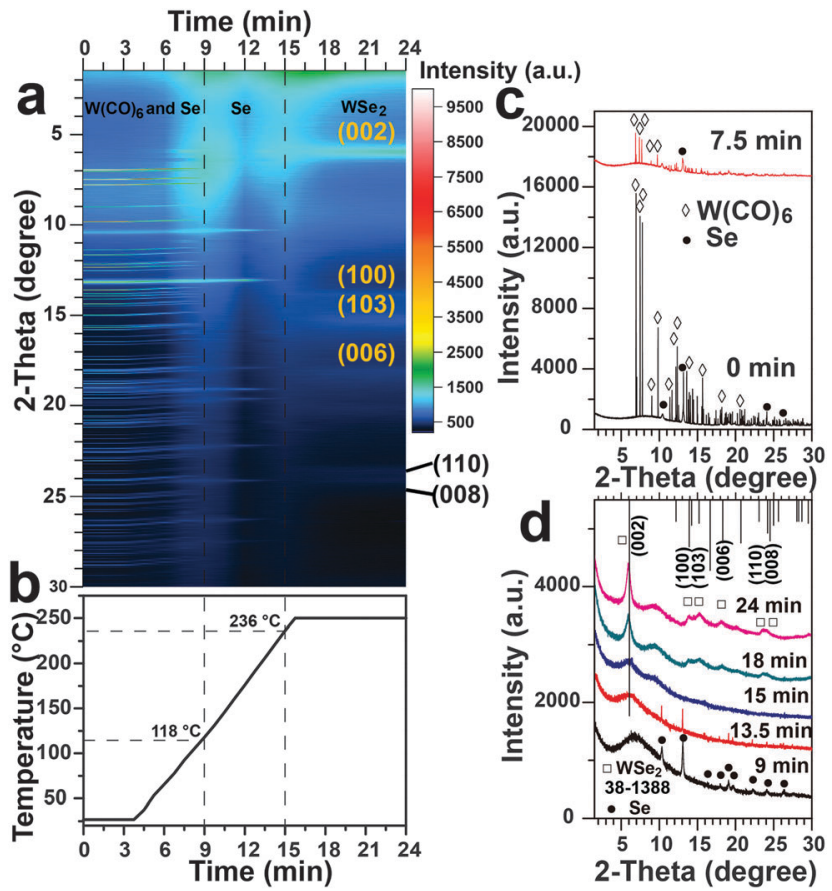

Fig. 3 (a) Time-resolved in situ SR-XRD patterns showing evolution from $\mathrm{W}(\mathrm{CO})_{6}$ and $\mathrm{Se}$ precursors to $\mathrm{WSe}_{2}$, (b) temperature ramp rate $\left(20{ }^{\circ} \mathrm{C} \mathrm{min}{ }^{-1}\right.$ ), (c and d) characteristic SR-XRD patterns of in situ products at the noted reaction time. Note that the reaction rate in the micro-reactor is much faster than that of the bulk solvothermal reaction in the autoclave.

remained in the phase of $\mathrm{W}(\mathrm{CO})_{6}$ (Fig. S10, ESI $\dagger$ ), with no evidence of a $\mathrm{W}$ intermediate.

To track the phase evolution as a function of reaction time, timeresolved in situ SR-XRD experiments were performed. The in situ SR-XRD is able to provide valuable real-time phase evolution during the reaction, ${ }^{1 e, 15}$ as illustrated in Scheme S1, ESI. $\dagger$ The in situ SR-XRD patterns of $\mathrm{WSe}_{2}$ (Fig. 3) demonstrate that the solvothermal process involves dissolution of $\mathrm{W}(\mathrm{CO})_{6}$, melting of Se and growth of flowerlike $\mathrm{WSe}_{2}$. The in situ SR-XRD patterns (Fig. 2a) of the starting precursors are readily indexed to the orthorhombic phase of $\mathrm{W}(\mathrm{CO})_{6}$ (JCPDS Card No. 40-0752) and hexagonal Se (JCPDS Card No. 06-0362), consistent with ex situ XRD patterns (Fig. S6, ESI $\dagger$ ).

Upon heating in $p$-xylene, the peaks of $\mathrm{W}(\mathrm{CO})_{6}$ continuously decreased in intensity and vanished after about $9 \mathrm{~min}$ at $118{ }^{\circ} \mathrm{C}$ (Fig. 3b-d). This temperature was much lower than the decomposition/melting point of $\mathrm{W}(\mathrm{CO})_{6}\left(\sim 170^{\circ} \mathrm{C}\right)$ indicating that $\mathrm{W}(\mathrm{CO})_{6}$ was neither melted nor completely decomposed into elemental tungsten. $\mathrm{W}(\mathrm{CO})_{6}$ was likely dissolved in $p$-xylene. The peaks of the Se precursor remained until the temperature reached $236{ }^{\circ} \mathrm{C}$ (above the melting point of Se, $221^{\circ} \mathrm{C}$ ), when the Se precursor peak disappeared instantly. $\mathrm{WSe}_{2}$ formed rapidly after the melting of Se. The elemental $\mathrm{W}$ intermediate arising from the decomposition of $\mathrm{W}(\mathrm{CO})_{6}$ proposed in the early literature was not detected. ${ }^{13,14}$ The formation mechanism determined from the in situ SR-XRD result agrees with the aforementioned ex situ SEM and XRD characterization. The heating rate governs the rate of Se melting and hence the whole reaction rate. Therefore, the reaction temperature plays a critical role in the formation of $\mathrm{WSe}_{2}$. Since evidence for the formation of $\mathrm{W}$ was not found in either ex situ or in situ experiments, we do not deem that the reaction between dissolved $\mathrm{W}(\mathrm{CO})_{6}$ and melted Se in $p$-xylene in this case followed the twostep process as proposed in the literature. ${ }^{13,14}$ The reaction mechanism might be a straightforward one-step reaction, or a modified two-step process initially involving the partial dissociation of $\mathrm{W}(\mathrm{CO})_{6}$ into $\mathrm{W}(\mathrm{CO})_{6-x},{ }^{16}$ and the subsequent oxidation by Se/S atoms. The underlying mechanism will be investigated in the future through advanced in situ techniques (e.g. mass spectrometry). Besides, agglomerate $\mathrm{WSe}_{2}$ with poor crystallinity (Fig. S11, ESI $\dagger$ ) was obtained when $\mathrm{W}(\mathrm{CO})_{6}$ reacted with Se without $p$-xylene, highlighting the importance of the $p$-xylene solvent in inducing the formation of flowerlike structures.

The growth process of $\mathrm{WS}_{2}$ was also explored by the in situ SR-XRD (Fig. S12, ESI $\dagger$ ). Sulfur (m.p. $115^{\circ} \mathrm{C}$ ) and $\mathrm{W}(\mathrm{CO})_{6}$ were dissolved at $83{ }^{\circ} \mathrm{C}$ and $116{ }^{\circ} \mathrm{C}$, respectively. Then $\mathrm{WS}_{2}$ was gradually formed and crystallized upon heating. Both precursors vanished below their melting or decomposition point and no $\mathrm{W}$ intermediate was detected, consistent with the results of $\mathrm{WSe}_{2}$.

The synthesis of $\mathrm{WTe}_{2}$ at $250^{\circ} \mathrm{C}$ with the solvothermal method using $\mathrm{W}(\mathrm{CO})_{6}$ and $\mathrm{Te}\left(\mathrm{m} . \mathrm{p} .450{ }^{\circ} \mathrm{C}\right)$ was attempted. However, the product was only a mixture of $\mathrm{Te}$ and $\mathrm{TeO}_{2}$ with $\mathrm{W}(\mathrm{CO})_{6}$, which was removed by rinsing with acetone (Fig. S13, ESI $\dagger$ ).

Based on the above ex situ and in situ experimental results, the growth of $\mathrm{WS}_{2}$ and $\mathrm{WSe}_{2}$ began with the dissolution of $\mathrm{S}$ and $\mathrm{W}(\mathrm{CO})_{6}$, melting of Se and then both precursors reacted quickly to produce crystalline $\mathrm{WS}_{2}$ and $\mathrm{WSe}_{2}$ under the solvothermal condition. The absence of complete dissociation of $\mathrm{W}(\mathrm{CO})_{6}$ into $\mathrm{W}$ in this work appears to defy the commonly accepted two-step reaction mechanism. ${ }^{13,14}$ The knowledge gained about the growth mechanism of tungsten sulfide and selenide by the time-resolved in situ SR-XRD technique will inspire new studies of various layered transition metal dichalcogenides.

These as-synthesized flowerlike $\mathrm{WSe}_{2}$ and $\mathrm{WS}_{2}$ microspheres possess many nanosheets and abundant chalcogen ligands with innate reactivity towards soft heavy metal ions $\left(\mathrm{Hg}^{2+}, \mathrm{Pb}^{2+}\right.$, $e t c$.) and structural rigidity. These features are desirable for the sequestration of heavy metal ions from water. The flowerlike $\mathrm{WSe}_{2}$ and $\mathrm{WS}_{2}$ microspheres were used to sequester various heavy metal ions, including $\mathrm{As}(\mathrm{V}), \mathrm{As}(\mathrm{III}), \mathrm{Cd}^{2+}, \mathrm{Pb}^{2+}$ and $\mathrm{Hg}^{2+}$, from water. They did not remove $\mathrm{As}(\mathrm{V}), \mathrm{As}(\mathrm{III})$ and $\mathrm{Cd}^{2+}$, whereas they exhibited high uptake capacities for $\mathrm{Hg}^{2+}$ and $\mathrm{Pb}^{2+}$. This is due to the innate selectivity of metal chalcogenides for soft heavy metal ions (i.e. $\mathrm{Hg}^{2+}$ and $\left.\mathrm{Pb}^{2+}\right) \cdot{ }^{11}$ Fig. 4 exhibits the variation in $\mathrm{Pb}^{2+}$ and

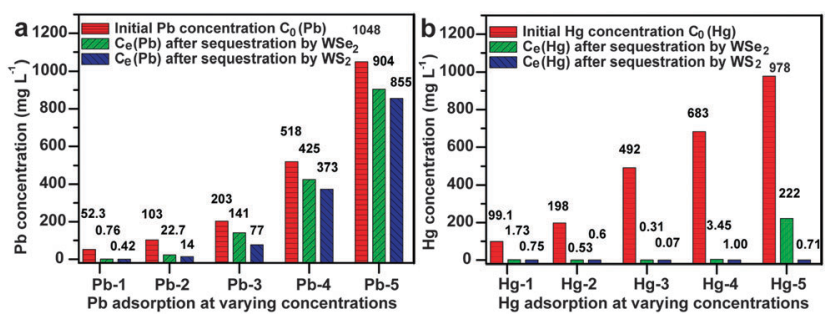

Fig. 4 (a) $\mathrm{Pb}^{2+}$ and (b) $\mathrm{Hg}^{2+}$ sequestration of $\mathrm{WSe}_{2}$ and $\mathrm{WS}_{2}$ in water. The WS $\mathrm{S}_{2}$ and $\mathrm{WS}_{2}$ content in the $\mathrm{Pb}^{2+}$ and $\mathrm{Hg}^{2+}$ aqueous solutions was $0.5 \mathrm{~g} \mathrm{~L}^{-1}$. 
$\mathrm{Hg}^{2+}$ concentrations before and after sequestration by $\mathrm{WSe}_{2}$ and $\mathrm{WS}_{2}$ samples at $0.5 \mathrm{~g} \mathrm{~L}^{-1}$. The $\mathrm{WSe}_{2}$ and $\mathrm{WS}_{2}$ were able to reduce the concentration of $\mathrm{Pb}^{2+}$ from $52.30 \mathrm{mg} \mathrm{L}^{-1}$ to 0.76 and $0.42 \mathrm{mg} \mathrm{L}^{-1}$ (Fig. 4a), respectively, giving a $\mathrm{Pb}^{2+}$ uptake capacity of ca. $103 \mathrm{mg} \mathrm{g}^{-1}$. The highest $\mathrm{Pb}^{2+}$ uptake capacities of $\mathrm{WSe}_{2}$ and $\mathrm{WS}_{2}$ are 288 and $386 \mathrm{mg} \mathrm{g}^{-1}$ when treating $1048 \mathrm{mg} \mathrm{L}^{-1}$ of lead ions in water, which are substantially higher than those of nanostructured adsorbents with abundant hydroxyl groups reported previously, such as urchin-like $\mathrm{FeOOH}\left(80 \mathrm{mg} \mathrm{g}^{-1}\right),{ }^{8 a}$ flowerlike zinc silicate (210 $\mathrm{mg} \mathrm{g}^{-1}$ ) and flowerlike AlOOH (124.2 $\mathrm{mg} \mathrm{g}^{-1}$ ) under similar conditions (Table S1, ESI $\dagger$ ). ${ }^{8 c, 10}$ Particularly, $\mathrm{WSe}_{2}$ and $\mathrm{WS}_{2}$ show extremely high uptake capacities for $\mathrm{Hg}^{2+}$ (Fig. 4b). $\mathrm{WSe}_{2}$ and $\mathrm{WS}_{2}$ could decrease the concentration of $\mathrm{Hg}^{2+}$ from $978 \mathrm{mg} \mathrm{L}^{-1}$ to $222 \mathrm{mg} \mathrm{L}^{-1}$ and $0.71 \mathrm{mg} \mathrm{L}^{-1}$ resulting in impressive capacities of $1512 \mathrm{mg} \mathrm{g}^{-1}$ and $1954 \mathrm{mg} \mathrm{g}^{-1}$, respectively. Their capacities for $\mathrm{Hg}^{2+}$ are significantly higher than those of conventional metal oxide and carbon-based adsorbents (Table S1, $\mathrm{ESI} \dagger$ ) and those of metal chalcogenides (Table S2, ESI $\dagger) .{ }^{11}$ Flowerlike $\mathrm{WSe}_{2}$ was characterized after removal of $\mathrm{Pb}^{2+}$ and $\mathrm{Hg}^{2+}$ (Fig. S14 $\& \mathrm{~S} 15, \mathrm{ESI} \dagger) . \mathrm{PbWO}_{4}$ polyhedron nanoparticles are embedded in the $\mathrm{WSe}_{2}$ nanosheets suggesting that $\mathrm{Pb}^{2+}$ ions were removed via a chemical reaction. When treating $\mathrm{Hg}^{2+}$ ions in water, the $\mathrm{WSe}_{2}$ nanosheets were almost fully covered by $\mathrm{Hg}_{2} \mathrm{Cl}_{2}$ and $\mathrm{Hg}_{3} \mathrm{Se}_{2} \mathrm{Cl}_{2}$ nanoparticles, suggesting that $\mathrm{WSe}_{2}$ is a reducing agent that has high reactivity towards $\mathrm{Hg}^{2+}$ leading to the high $\mathrm{Hg}^{2+}$ uptake capacity. Likewise, $\mathrm{PbWO}_{4}$ nanoparticles are immobilized on $\mathrm{WS}_{2}$ nanosheets (Fig. S16 \& S17, ESI $\dagger$ ). $\mathrm{WS}_{2}$ microspheres are enclosed by as-formed $\mathrm{Hg}_{3} \mathrm{~S}_{2} \mathrm{Cl}_{2}$ and $\mathrm{Hg}_{2} \mathrm{Cl}_{2}$ particles, indicating extremely high reactivity and reducibility of $\mathrm{WS}_{2}$ towards $\mathrm{Hg}^{2+}$ ions, which resulted in such a high $\mathrm{Hg}^{2+}$ sequestration capacity. The $\mathrm{WS}_{2}$ microsphere is superior to the flowerlike $\mathrm{WSe}_{2}$ in terms of uptake capacities for $\mathrm{Pb}^{2+}$ and $\mathrm{Hg}^{2+}$, possibly because sulfide has higher reactivity towards $\mathrm{Pb}^{2+}$ and $\mathrm{Hg}^{2+}$ than selenide. This mechanism is different from the direct cation exchange mechanism of other metal chalcogenides for heavy metal ion sequestration. ${ }^{11}$

In summary, flowerlike $\mathrm{WSe}_{2}$ and $\mathrm{WS}_{2}$ microspheres assembled of nanosheets were synthesized by a facile and high-yield solvothermal method. The in situ SR-XRD gave insights into the growth mechanism of the flowerlike $\mathrm{WSe}_{2}$ and $\mathrm{WS}_{2}$, which is the reaction between dissolved $\mathrm{W}(\mathrm{CO})_{6}$ and dissolved $\mathrm{S}$ or melted Se without complete decomposition of $\mathrm{W}(\mathrm{CO})_{6}$ into a $\mathrm{W}$ intermediate. Flowerlike $\mathrm{WSe}_{2}$ and $\mathrm{WS}_{2}$ microspheres were used for heavy metal ion sequestration and exhibited remarkable uptake capacities for $\mathrm{Pb}^{2+}\left(288 \mathrm{mg} \mathrm{g}^{-1}\right.$ for $\mathrm{WSe}_{2}$ and $386 \mathrm{mg} \mathrm{g}^{-1}$ for $\mathrm{WS}_{2}$ ) and $\mathrm{Hg}^{2+}\left(1512 \mathrm{mg} \mathrm{g}^{-1}\right.$ for $\mathrm{WSe}_{2}$ and $1954 \mathrm{mg} \mathrm{g}^{-1}$ for $\mathrm{WS}_{2}$ ), showing great potential in heavy metal remediation. The synthesis method and SR-XRD characterization in this work offer novel approaches towards rational design and fabrication of hierarchical transition metal dichalcogenides and understanding of their formation mechanism.

This project received financial support from Joint Research Project funding (GJHZ1224) from the Chinese Academy of Sciences and CSIRO. We acknowledge the Australian Synchrotron for the Powder Diffraction beamline access, and CSIRO Minerals for laboratory in situ XRD access. The CSIRO Office of the Chief Executive (OCE) Postdoctoral and Science Leader Schemes are acknowledged for supporting this work. R. A. C. acknowledges the Australian Research Council for a Future Fellowship (FT0990583).

\section{Notes and references}

1 (a) Q. H. Wang, K. Kalantar-Zadeh, A. Kis, J. N. Coleman and M. S. Strano, Nat. Nanotechnol., 2012, 7, 699-712; (b) X. Huang, Z. Y. Zeng and H. Zhang, Chem. Soc. Rev., 2013, 42, 1934-1946; (c) R. Lv, J. A. Robinson, R. E. Schaak, D. Sun, Y. Sun, T. E. Mallouk and M. Terrones, Acc. Chem. Res., 2015, 48, 56-64; (d) M. R. Gao, Y. F. Xu, J. Jiang and S. H. Yu, Chem. Soc. Rev., 2013, 42, 2986-3017; (e) J. Song, F. Xia, M. Zhao, Y. L. Zhong, W. Li, K. P. Loh, R. A. Caruso and Q. Bao, Chem. Mater., 2015, 27, 3471-3482; $(f)$ X. Liu, J. Xu, Z. Fang, L. Lin, Y. Qian, Y. Wang, C. Ye, C. Ma and J. Zeng, Nano Res., 2015, 8, 3612-3620.

2 J. Kim, X. P. Hong, C. H. Jin, S. F. Shi, C. Y. S. Chang, M. H. Chiu, L. J. Li and F. Wang, Science, 2014, 346, 1205-1208.

3 (a) B. Liu, T. Luo, G. Y. Mu, X. F. Wang, D. Chen and G. Z. Shen, ACS Nano, 2013, 7, 8051-8058; (b) D. Chen, G. Ji, B. Ding, Y. Ma, B. Qu, W. Chen and J. Y. Lee, Nanoscale, 2013, 5, 7890-7896.

4 (a) H. T. Wang, D. S. Kong, P. Johanes, J. J. Cha, G. Y. Zheng, K. Yan, N. A. Liu and Y. Cui, Nano Lett., 2013, 13, 3426-3433; (b) K. Xu, F. M. Wang, Z. X. Wang, X. Y. Zhan, Q. S. Wang, Z. Z. Cheng, M. Safdar and J. He, ACS Nano, 2014, 8, 8468-8476; (c) L. Cheng, W. J. Huang, Q. F. Gong, C. H. Liu, Z. Liu, Y. G. Li and H. J. Dai, Angew. Chem., Int. Ed., 2014, 53, 7860-7863.

5 (a) J. R. McKone, A. P. Pieterick, H. B. Gray and N. S. Lewis, J. Am. Chem. Soc., 2013, 135, 223-231; (b) Y. H. Sang, Z. H. Zhao, M. W. Zhao, P. Hao, Y. H. Leng and H. Liu, Adv. Mater., 2015, 27, 363-369.

6 L. X. Lin, Y. X. Xu, S. W. Zhang, I. M. Ross, A. C. M. Ong and D. A. Allwood, ACS Nano, 2013, 7, 8214-8223.

7 (a) T. Georgiou, R. Jalil, B. D. Belle, L. Britnell, R. V. Gorbachev, S. V. Morozov, Y. J. Kim, A. Gholinia, S. J. Haigh, O. Makarovsky, L. Eaves, L. A. Ponomarenko, A. K. Geim, K. S. Novoselov and A. Mishchenko, Nat. Nanotechnol., 2013, 8, 100-103; (b) H. Fang, S. Chuang, T. C. Chang, K. Takei, T. Takahashi and A. Javey, Nano Lett., 2012, 12, 3788-3792.

8 (a) B. Wang, H. Wu, L. Yu, R. Xu, T.-T. Lim and X. W. Lou, Adv. Mater., 2012, 24, 1111-1116; (b) H. Li, W. Li, Y. Zhang, T. Wang, B. Wang, W. Xu, L. Jiang, W. Song, C. Shu and C. Wang, J. Mater. Chem., 2011, 21, 7878-7881; (c) Y.-X. Zhang, Y. Jia, Z. Jin, X.-Y. Yu, W.-H. Xu, T. Luo, B.-J. Zhu, J.-H. Liu and X.-J. Huang, CrystEngComm, 2012, 14, 3005-3007; (d) S. Hu, W. Chen, J. Zhou, F. Yin, E. Uchaker, Q. Zhang and G. Cao, J. Mater. Chem. A, 2014, 2, 7862-7872; (e) W. Li, D. H. Chen, F. Xia, J. Z. Y. Tan, P.-P. Huang, W.-G. Song, N. M. Nursam and R. A. Caruso, Environ. Sci.: Nano, 2016, 3, 94-106; $(f)$ X. Li, W. Li, M. Li, P. Cui, D. H. Chen, T. Gengenbach, L. Chu, H. Liu and G. Song, J. Mater. Chem. A, 2015, 3, 2762-2769; (g) C. Chen, Y. Yu, W. Li, C. Cao, P. Li, Z. Dou and W.-G. Song, J. Mater. Chem., 2011, 21, 12836-12841.

9 (a) A. Prabakaran, F. Dillon, J. Melbourne, L. Jones, R. J. Nicholls, P. Holdway, J. Britton, A. A. Koos, A. Crossley, P. D. Nellist and N. Grobert, Chem. Commun., 2014, 50, 12360-12362; (b) Z. L. Yang, D. Q. Gao, J. Zhang, Q. Xu, S. P. Shi, K. Tao and D. S. Xue, Nanoscale, 2015, 7, 650-658.

10 J. Qu, C.-Y. Cao, Y.-L. Hong, C.-Q. Chen, P.-P. Zhu, W.-G. Song and Z.-Y. Wu, J. Mater. Chem., 2012, 22, 3562-3567.

11 (a) I. R. Pala and S. L. Brock, ACS Appl. Mater. Interfaces, 2012, 4, 2160-2167; (b) M. J. Manos, C. D. Malliakas and M. G. Kanatzidis, Chem. - Eur. J., 2007, 13, 51-58; (c) M. J. Manos, V. G. Petkov and M. G. Kanatzidis, Adv. Funct. Mater., 2009, 19, 1087-1092; (d) C. W. Abney, J. C. Gilhula, K. Lu and W. Lin, Adv. Mater., 2014, 26, 7993-7997; (e) M. J. Manos and M. G. Kanatzidis, Chem. - Eur. J., 2009, 15, 4779-4784.

12 N. D. Boscher, C. J. Carmalt and I. P. Parkin, J. Mater. Chem., 2006, 16, 122-127.

13 D. Duphil, S. Bastide, J. C. Rouchaud, J. L. Pastol, B. Legendrel and C. Levy-Clement, Nanotechnology, 2004, 15, 828-832.

14 S. V. Pol, V. G. Pol, J. M. Calderon-Moreno and A. Gedanken, J. Phys. Chem. C, 2008, 112, 5356-5360.

15 W. Li, F. Xia, J. Qu, P. Li, D. H. Chen, Z. Chen, Y. Yu, Y. Lu, R. A. Caruso and W.-G. Song, Nano Res., 2014, 7, 903-916.

16 N. Wiberg and A. F. Holleman, Inorganic Chemistry, 2001, Academic Press. 